\title{
Study on the Construction of the Discipline Construction Theory System of the Local Philology in University Library
}

\author{
Jingmei Zhang \\ Library of Baoshan College, Baoshan, Yunnan, 678000, China.
}

279619568@qq.com

\begin{abstract}
Keywords: University library; Local literature study; Discipline construction; Theory system; Structure
\end{abstract}

\begin{abstract}
The discipline construction of the Local Philology in university library is a long-term systematic project, and its theoretical system can be constructed from three aspects of macro, meso and micro levels. The macro level of the Local Philology discipline construction includes: determining the subject construction positioning, determining the subject construction objective, choosing the subject direction, making the development plan of discipline construction; The discipline construction of the Local Philology in the middle layer includes: the construction of the organization, the construction of the discipline team, the construction of the discipline base, the construction of scientific research work and the construction of the discipline system; The discipline construction of the Local Philology on the micro level includes: construction leading group, the selection of academic leaders, the organization of academic research team, to do a good job discipline base construction, scientific research project construction, improve discipline construction system and subject construction evaluation index system and so on.
\end{abstract}

\section{Introduction}

The nature and orientation of university library is an academic institution serving for teaching and scientific research. University Library to carry out academic research and discipline construction and other high knowledge content of the activities, is an important manifestation of its academic functions, is also an important manifestation of the level and grade of its office. Nowadays, with the rapid development of scientific research and information technology, discipline construction has become one of the key issues to adapt to the development of university libraries. High level of university library should not only with first-class service provided and a high level of science research, but also as discipline construction, and to make the service, into fruit and disciplines infiltration, dependency, form a benign development of discipline system[1].The construction of local literature is an important content of the construction of characteristic collection of university library, local literature is a universal law of the construction of local literature in the exploration and summary, is the embodiment of the construction of theory system and centralized, concrete construction and the theoretical basis and practical guidance. University library is the construction of the local literature line departments, with professional staff, technical means, literature resources, academic environment, discipline construction should give full play to the its research functions, integration of a variety of advantages of local literature discipline construction, to improve its academic research level and quality of service at the same time, promote the maturity and development of the discipline theory of local literature.

Discipline construction is the higher school focuses on the academic nature set direction of discipline, disciplinary research, faculty, talent training, academic exchange and base condition is equal to one of the comprehensive construction, the purpose is the subject has a certain level, the formation of scientific research, personnel training and service to the community, the comprehensive strength[2].The University Library and the construction of disciplines for binding studies are more concentrated in the library how better provide services to university's discipline construction, uncommon for university library by introducing the concept and practice of discipline construction, University Library as a discipline construction in the bearing arm body discipline 
construction of relevant research results. Therefore, the research group the discipline construction of University Library as the research target, subject construction of local literature as the breakthrough point, try to construction of university library local literature science theory system of discipline construction, in order to provide theoretical reference for the University Library discipline construction research and practice.

\section{Analysis on the Particularity of Subject Construction in University Library}

Discipline construction is the basic construction of the University's strategic position, and it is the head of the development of university construction. Subject construction is a research topic in the field of higher education research is important and related theoretical research, rich and mature, provide a wealth of valuable research results for the study of the discipline construction of university library. While at the same time, colleges and universities library belongs to the school teaching department, as subject of subject construction for the discipline construction has certain particularity. Therefore, we in the introduction of the discipline construction of theoretical research results of the existing, must pay attention to the analysis of University Library Local Literature Discipline Construction, organic combination of the two, to construct reasonable local literature study discipline theoretical system.

Analysis on the Advantages of the Construction of the Local Documents in University Library. University library is the document information center of the University, of discipline construction have certain resources, such as information of professional and technical personnel, advanced retrieval techniques, rich literature resources and the convenient talent network resources such as. University library is an important position in the construction of local literature, in the first line of local literature, with a number of specialized personnel engaged in the construction of local literature and research work for a long time. University Library to carry out the subject construction of local literature, the subject study and practice of combining work, is conducive to the promotion of academic research achievements inspection, promotion and application, the resources construction of the library, knowledge service, scientific research and discipline construction mutual penetration and mutual promotion, form the benign development of the discipline system.

The Basic Task and Ultimate Goal of the Construction of the Local Document of University Library. "The regulation of the colleges and Universities Library (Amendment)"clearly pointed out that nature and localization of university library is for teaching and scientific research service provided the academic institutions, both service and academic the dual attribute, the service is the essential attribute of, the academic is the prerequisite and the basic conditions of the high level and high quality service. University Library to carry out the discipline construction is an important embodiment of the academic functions to serve the functions of the service. University Library in the development of discipline construction, the establishment of local philology subject construction of the ultimate goal, we must fully consider the nature of the service, will promote the construction of local literature, improvement of library service quality and level, and better for the teaching, scientific research and social service for subject construction of the starting point, the fundamental task and the final destination. This final goal is determined, which is different from the university discipline construction with the talent training as the basic task and the final goal setting, which is determined by the essential attribute of University Library's service nature.

The Level and Complexity of the Construction of the Local Document Discipline in the University Library. First, discipline team construction. University Library's own function is to carry out the construction of literature resources and to provide information resource service, university library staff in academic research at the same time, but also bear a lot of business, not all the time and effort into research on discipline construction. On the other hand, due to historical reasons and other factors influence, University Library widespread staff's professional quality and academic level is uneven, the lack of subject leaders and the backbone of academic research, subject construction and talent has a certain level. These factors make the construction of the university library to carry out the construction of local literature discipline has some difficulties and challenges, so that the construction of the local literature discipline team is more hierarchical and 
complex. Second, the construction of the discipline base. Base construction is the important content of subject construction, University Library's local literature subject base should include research base and service base of two sections, of which service base construction relates to the business process of the library's local literature construction that involved in the work of the library, with considerable complexity.

\section{Theoretical Framework of the Construction of Local Documents in Academic Libraries}

Discipline construction is around the direction of discipline, discipline team and base, through the investment and accumulation of software and hardware, raise the level of discipline and enhance personnel training, scientific research and social service comprehensive strength as a system engineering construction [2]. The theory system of the subject construction of local documents can be constructed from three aspects of macro, medium and micro level. Macro discipline construction includes positioning of discipline construction, the goal of the determined choice of subject direction, discipline development plan formulation; the discipline construction of meso level including organization construction, faculty construction, base construction of subject and construction of scientific research and discipline system construction; construction of micro level is medium level construction of specific refinement and Implementation, including the implementation of the construction of specific programs, such as the establishment of discipline construction leading group, the selection of subject leaders, training academic innovation team, strengthen the construction of discipline research institutions.

\section{Analysis on the Theoretical System of the Construction of Local Documents in University Library}

The Construction of Local Literature Study in Macro Level. The construction of the local document science subject in the macro level includes three aspects: the orientation of discipline construction, the determination of the goal, the choice of the subject direction and the development of the discipline. The discipline construction positioning, that is, to determine the university library local literature study discipline construction in discipline construction in Colleges and universities to locate the target to achieve the kind of discipline construction target (such as a university subject characteristics and subject advantages and key disciplines, or provincial key cultivation subject characteristics, national level key cultivating subject characteristics).Orientation of discipline construction, considering the subject development level, development potential, University Library discipline construction conditions and the scale, teaching goal and orientation, discipline construction environmental conditions, demand for social services and other factors, comprehensive analysis, determine the scientific and reasonable target location. This goal orientation is one of the macro goals of discipline construction. Discipline construction goal is the driving force and direction of the subject construction. University Library's local literature study discipline construction to determine the combined with local literature itself the subject and the reality of the development of University Library and the discipline construction of environmental conditions, based on the long-term planning, develop advanced, forward-looking, scientific and level of discipline construction target system. The content of the target system should be divided according to the scope of concept, including the macroscopic and microscopic objectives. The classification of the target system should include short term goal, medium term and long term goal. Among them, the macro goal is to follow the general rules of the development of the discipline construction, service science and technology, economy and the goal of the development of colleges and Universities [3].The choice of subject direction is the foundation of the discipline construction. Local literature is a literature theory based, widely used edition, compilation, collation, bibliography and local chronicles and computer science and knowledge, the regional literature generation, distribution, features, communication, gathering, development, the entire sequence and development using research, and explore the law of development of a subject [4]. The strategic planning of discipline development. The university library should establish a scientific and rational 
development plan for the science and the rational development of the local document science based on the determination of the orientation, the goal and the subject orientation of the subject construction. Planning is the guidance of practice and subject development planning should include the target system of discipline construction and the realization of the goal of the construction steps of, its content shall cover the specific planning of discipline construction of each organic part, such as the organization of construction planning, team discipline construction planning and research work of the construction planning, the base discipline construction planning and discipline system construction planning.

The Construction of the Local Literature Subject in the Middle Layer. In discipline construction, academic team is the key and the base of organization and discipline is to support, scientific research project is the carrier, the discipline system is the guarantee, which complement each other, together constitute an organic whole of discipline construction.

The Construction of Local Literature Study in Micro Level. Micro level of local literature study discipline construction content includes: establishment of discipline construction leading group; the selection of subject leaders, organization, construction of academic research team; focus on teaching base construction; attach importance to the construction of scientific research project; perfect system of discipline construction and subject construction evaluation index system of five aspects of content.

\section{Epilogue}

To sum up, the University Library's local literature science discipline construction is a strategic, global, comprehensive, challenging and long-term system engineering, related work has heavy responsibilities. University library must be based on reality of long-term planning, will continue to explore science, the physical mechanism of the discipline construction, only in this way in order to make the local literature discipline construction on a sustained and healthy benign development.

\section{Acknowledgements}

This paper is the 2014 stage of the Yunnan Provincial Department of Education Research Fund Project "the research on the construction of local documents in University Library"(No.2014Y483).

\section{References}

[1] Wu Sanlin. Dialectical Relationship between College Library Construction and Library Science Research \& Discipline Development [J].Shanxi Library Journal, 2006(6):8-10.

[2] Lu Jun, Song Xiaoping, Lu Shuyun. Discussion of Relevant Concepts on Disciplines and Disciplines Building [J].Tsinghua Journal of Education, 2004 (6):12-15.

[3] Xu Bihong. Research on the Discipline Construction of Sports Engineering in China Universities [D].China University of Mining and Technology, 2012.

[4] Liu Jihong. Historical Outline and Connotation Analysis of the Definition of Local Philology [J].Journal of Baoshan College, 2013(4):102-104. 